\title{
ROTENOIDS FROM Tephrosia toxicaria WITH LARVICIDAL ACTIVITY AGAINST Aedes aegypti, THE MAIN VECTOR OF DENGUE FEVER
}

Jackson Nunes e Vasconcelos

Instituto Federal de Educação, Ciência e Tecnologia do Ceará, Campus Tianguá, Rod. CE-187, s/n, 62320-000 Tianguá - CE, Brasil Gilvandete Maria Pinheiro Santiago

Departamento de Farmácia, Faculdade de Farmácia, Odontologia e Enfermagem, Universidade Federal do Ceará, Rua Capitão Francisco Pedro, 1210, 60430-370 Fortaleza - CE, Brasil

Jefferson Queiroz Lima, Jair Mafezoli, Telma Leda Gomes de Lemos, Francisca Renata Lopes da Silva, Mary Anne Sousa Lima, Antônia Torres Ávila Pimenta, Raimundo Braz-Filho\# e Angela Martha Campos Arriaga*

Departamento de Química Orgânica e Inorgânica, Centro de Ciências, Universidade Federal do Ceará, CP 12200, 60021-970 Fortaleza - CE, Brasil

\section{Dari Cesarin-Sobrinho}

Departamento de Química, Instituto de Ciências Exatas, Universidade Federal Rural do Rio de Janeiro, 23890-971 Seropédica RJ, Brasil

Recebido em 29/6/11; aceito em 14/1/12; publicado na web em 15/5/12

In the search for new larvicides from plants, we have investigated the potential activity of the rotenoids deguelin (1), 12a-hydroxy- $\alpha$ toxicarol (2) and tephrosin (3), isolated from the bioactive ethanol extract of roots of Tephrosia toxicaria Pers., against Aedes aegypti, the main vector of dengue. The absolute configuration of these compounds was determined by circular dichroism (CD) spectra. The $\mathrm{LC}_{50}$ values of the compounds evaluated justify the potential of $T$. toxicaria as a new natural larvicide.

Keywords: Tephrosia toxicaria; rotenoids; Aedes aegypti.

\section{INTRODUCTION}

Aedes aegypti is considered a vector of dengue and yellow fever, endemic diseases found more commonly in Africa, Asia and South America. Estimates suggest that, 50 million dengue cases, 500,000 of which correspond to its most serious form, dengue hemorrhagic fever, occur annually. ${ }^{1}$ The present resurgence of this disease is due to the higher number of breeding places in today's throwaway society. Yellow fever has been brought under relatively good control but there are no specific therapeutic agents for this disease. Moreover, no vaccine is available against dengue, ${ }^{2}$ its control being restricted to combating the vector by attacking the larval breeding grounds. ${ }^{3}$ The proliferation of this disease is partly due to increasing resistance of mosquitoes to current commercial insecticides such as Temephos ${ }^{\circledR}$, a nonsystemic organophosphorus insecticide.

Although several plants from different families have been reported as exerting mosquitocidal activity, only a few botanicals have made the transition from laboratory to field use, such as the Neem (Azadirachta indica A. Juss.) insecticide. ${ }^{4}$ Botanical pesticides have been used traditionally by human communities in many parts of the world and many plants produce secondary metabolites that inhibit the growth of insects. ${ }^{5}$ Despite the immense resource presented by the natural flora of Brazil, control of A. aegypti still depends basically on the use of synthetic pesticides. ${ }^{6}$ These compounds are toxic and adversely affect the environment by contaminating soil, water and air. It is noteworthy that the chemicals derived from plants have been projected as part of the arsenal of weapons in future mosquito control programs, because these bioactive compounds are biodegradable into nontoxic products and are potentially suitable for use in integral pest management programs. ${ }^{7}$

*e-mail: angelamcarriaga@yahoo.com.br

"Emeritus visiting Professor - FAPERJ/UENF/UFRRJ
Tephrosia toxicaria Pers., a member of the Leguminosae family, is a shrub popularly known as "timbó de caiena" or "anil". The aqueous extract from its roots is used as an agrochemical in organic gardens in Ceará State of Northeast Brazil, where it is cultivated.

Earlier studies reported that flavonoids, particularly rotenoids, are an interesting class of compounds showing insecticide activity. ${ }^{8,9}$ Previous investigations by our group have assessed the toxicity of essential oils, ${ }^{10}$ several extracts, fractions and compounds isolated from the root extract of $T$. toxicaria against Aedes aegypti larvae. ${ }^{11}$ As part of our research on the identification of new insecticides derived from plants, ${ }^{12}$ the present study was carried out to determine the larvicidal activity of the rotenoids deguelin (1), ${ }^{13}$ 12a-hydroxy- $\alpha$ toxicarol (2) ${ }^{13}$ and tephrosin (3) ${ }^{14}$ (Figure 1) isolated from root extract of T. toxicaria. Additionally, this study allowed the comparison of the larvicidal potential of these compounds with those previously isolated ${ }^{11}$ and with two standards insecticides: Rotenone ${ }^{\circledast}$ and the synthetic insecticide Temephos ${ }^{\circledR}$.

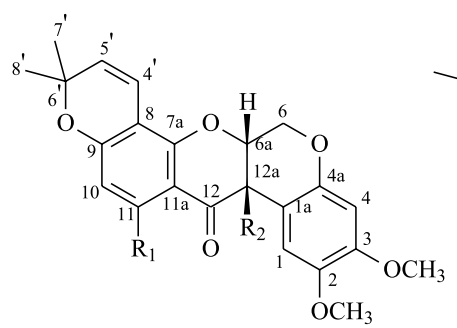

$1 \quad \mathrm{R}_{1}=\mathrm{R}_{2}=\mathrm{H}$

$2 \mathrm{R}_{1}=\mathrm{R}_{2}=\mathrm{OH}$

$3 \quad \mathrm{R}_{1}=\mathrm{H} ; \mathrm{R}_{2}=\mathrm{OH}$

$4 \quad \mathrm{R}_{1}=\mathrm{OH} ; \mathrm{R}_{2}=\mathrm{H}$<smiles>COc1cc2c(cc1OC)-c1c(oc3c4c(cc(O)c3c1=O)OC(C)(C)C=C4)CO2</smiles>

5
Figure 1. Rotenoids isolated of Tephrosia toxicaria Pers. 
These results can be useful to help promote research aimed at the development of new insecticides agents for mosquito control based on bioactive chemical compounds from plants.

\section{EXPERIMENTAL}

\section{General experiment procedures}

\section{HPLC analysis}

The HPLC equipment used was an Shimadzu ${ }^{\circledR}$ LC-20AT system including a SPD-M20A photodiode array detection (DAD) system (detection at 210-400 $\mathrm{nm}$ ). The column used was a reversed-phase Phenomenex ${ }^{\circledR}$ RP-18 (250 x 10 mm, $5 \mu \mathrm{m}$ ), using an MeOH-0,1\% acid formic aqueous system (4:1) as a mobile phase in isocratic mode at a flow rate of $1.0 \mathrm{~mL} / \mathrm{min}$.

\section{NMR spectro}

A Bruker ${ }^{\circledR}$ Avance DRX 500 spectrometer, operating at $500 \mathrm{MHz}$ for ${ }^{1} \mathrm{H}$ and $125 \mathrm{MHz}$ for ${ }^{13} \mathrm{C} \mathrm{NMR}$ was used for experiments $1 \mathrm{D}$ and 2D with chemical shifts given in ppm. All spectra were run using $\mathrm{CDCl}_{3}$ as the solvent. Chemical shifts, measured on the $\delta$ scale, were referenced to the residual undeuterated portion of the deuterated solvent for proton $\left(\delta_{\mathrm{H}} 7.27\right)$ and the center peak of the deuterated chloroform carbons $\left(\delta_{\mathrm{C}} 77.23\right)$.

\section{Mass spectra}

Mass spectra were obtained with a Shimadzu ${ }^{\circledR}$ QP 5000/DI-50 spectrometer by using a direct insertion probe.

\section{Circular dichroism}

Circular dichroism (CD) was obtained in $\mathrm{CH}_{3} \mathrm{CN}$ on a Jasco 815 spectrometer, TFD-425S 15 at $30{ }^{\circ} \mathrm{C}$.

\section{Plant material}

Tephrosia toxicaria Pers. was collected in Guaraciaba do Norte, Ceará State, Brazil. A voucher specimen (\# 32.139) was deposited at the Prisco Bezerra Herbarium, Universidade Federal do Ceará (UFC).

\section{Extraction and isolation of compounds}

The air-dried, powdered roots (109.0 g), were extracted with $95 \% \mathrm{EtOH}$ at room temperature. After filtration, the solvent was removed under a vacuum to yield $16.0 \mathrm{~g}$ of EtOH extract, subsequently subjected to column chromatography over silica gel (Merck 60-120 Mesh) using hexane, $\mathrm{CHCl}_{3}, \mathrm{EtOAc}$ and $\mathrm{MeOH}$. The fraction $\mathrm{CHCl}_{3}(7.0 \mathrm{~g})$ was chromatographed on a silica gel column and successively eluted with a stepwise gradient of hexane/ $\mathrm{CHCl}_{3}(0$, 20, 50 and 90\%). The fraction eluted with $20 \%$ furnished 1 (545.2 $\mathrm{mg}$ ). The fraction eluted with $50 \%$ was purified by reversed-phase HPLC using MeOH-HCOOH 0.1\% (4:1 v/v) as the mobile phase. This operation was repeated several times, yielding the compounds $\mathbf{2}(28.8 \mathrm{mg})$ and $\mathbf{3}(62.0 \mathrm{mg})$.

The roots $(500.0 \mathrm{~g})$ were extracted with water $(500 \mathrm{~mL})$ under reflux; the aqueous extract was submitted to successive extractions by ethyl acetate $(3 \times 250 \mathrm{~mL})$ producing, after recrystallization under $\mathrm{MeOH}, \alpha$-toxicarol $\mathbf{4}^{11,15}(7.4 \mathrm{mg})$. Compound 4 and $6 a, 12 a-d e h y d r o-\alpha$-toxicarol (5) were also obtained from the roots ethanolic extract. The details of the method for isolation of these compounds have been described previously. ${ }^{11}$

The structures of all compounds were established by $1 \mathrm{D}{ }^{1} \mathrm{H}$ and ${ }^{13} \mathrm{C}\left(\left\{{ }^{1} \mathrm{H}\right\}\right.$ and DEPT $)$ and $2 \mathrm{D}{ }^{1} \mathrm{H}-{ }^{1} \mathrm{H}-\mathrm{COSY}$, HSQC and HMBC NMR spectral data and by comparing their spectroscopy data with that reported in the literature. The cis $\mathrm{B} / \mathrm{C}$-ring junction of all the rotenoids was established by ${ }^{1} \mathrm{H}$ NMR spectroscopic analysis and their absolute configuration of the $\beta$-C6a and $\beta-\mathrm{C} 12 \mathrm{a}$ were determined based on CD data.

\section{Deguelin $(\mathbf{1})^{13}$}

Yellow amorphous solid; mp 153.4-156.2 ${ }^{\circ} \mathrm{C}$; EI/MS $\mathrm{m} / \mathrm{z}$ (Int. rel.): 394 ([M] $\left.]^{+}, 10\right), 192$ (100), 187 (52), 177 (31), 131 (19), 121 (19), 103 (21), 91 (23), 77 (43), 69 (30), 49 (72); ${ }^{1} \mathrm{H}$ NMR $(500 \mathrm{MHz}$, $\left.\mathrm{CDCl}_{3}\right)-\delta$ (multiplicity, $J \mathrm{~Hz}$ ): 7.75 (d, 9.2, H-11), 6.80 (s, H-1), 6.65 (d, 10.0, H-4'), 6.47 (s, H-4), 6.47 (d, 9.2, H-10), 5.56 (d, 10.0, H-5'), 4.92 (t, 3.1, H-6a), 4.64 (dd, 12.0, 3.1, H-6 ${ }_{\text {ax }}$ ), 4.19 (d, 12.0, H-6 $\mathrm{eq}), 3.85$ (d, 3.9, H-12a), $3.81\left(\mathrm{~s}, \mathrm{OCH}_{3}-3\right), 3.78\left(\mathrm{~s}, \mathrm{OCH}_{3}-2\right)$, 1.46 (s, H-8'), 1.39 (s, H-7'); $\left.{ }^{13} \mathrm{C} \mathrm{NMR} \mathrm{(125} \mathrm{MHz,} \mathrm{CDCl}_{3}\right): \delta 189.5$ (C-12), 160.3 (C-9), 157.2 (C-7a), 149.8 (C-3), 147.7 (C-4a), 144.1 (C-2), 128.9 (C-5'), 128.8 (C-11), 116.0 (C-4'), 113.0 (C-11a), 111.7 (C-10), 110.8 (C-1), 109.4 (C-8), 105.0 (C-1a), 101.2 (C-4), 77.9 (C-6'), 72.8 (C-6a), $66.5(\mathrm{C}-6), 56.6\left(\mathrm{OCH}_{3}-2\right), 56.1\left(\mathrm{OCH}_{3}-3\right), 44.6$ (C-12a), 28.5 (C-8'), 28.4 (C-7').

\section{2a-hydroxy- $\alpha$-toxicarol $(2)^{13}$}

Yellow crystal solid; $\mathrm{mp} 133.6-134.8{ }^{\circ} \mathrm{C}$; EI/MS $\mathrm{m} / z$ (Int. rel.): $426\left(^{(\mathrm{M}]^{+}}, 16\right), 408$ (5), 393 (11), 219 (11), 208 (100), 192 (29), 165 (16), 86 (22), 84 (33), 69 (20), 49 (43); ${ }^{1} \mathrm{H}$ NMR (500 MHz, $\mathrm{CDCl}_{3}$ ) $-\delta$ (multiplicity, $J \mathrm{~Hz}$ ): 11.63 (s, OH-11), 6.72 (s, H-1), 6.51 (d, 10.0, H-4'), 6.48 (s, H-4), 5.97 (s, H-10), 5.47 (d, 10.0, H-5'), 4.60 (dd, 12.0, 2.5, H-6 ${ }_{\mathrm{ax}}$ ), 4.54 (d,1.5, H-6a), 4.47 (dd, 12.0, $\left.0.5, \mathrm{H}-6_{\mathrm{eq}}\right), 4.17$ (s, OH-12a), $3.82\left(\mathrm{~s}, \mathrm{OCH}_{3}-3\right), 3.75$ (s, $\left.\mathrm{OCH}_{3}-2\right)$, 1.43 (s, H-8'), 1.36 (s, H-7'); ${ }^{13} \mathrm{C}$ NMR (125 MHz, $\left.\mathrm{CDCl}_{3}\right): \delta 195.0$ (C-12), 164.2 (C-11), 163.7 (C-9), 155.7 (C-7a), 151.5 (C-3), 148.5 (C-4a), 144.2 (C-2), 126.8 (C-5'), 115.2 (C-4'), 109.6 (C-1), 108.6 (C-1a), 102.2 (C-8), 101.4 (C-4), 100.1 (C-11a), 98.1 (C-10), 78.8 (C-6'), 75.9 (C-6a), 67.0 (C-12a), 63.8 (C-6), $56.6\left(\mathrm{OCH}_{3}-2\right), 56.0$ $\left(\mathrm{OCH}_{3}-3\right), 28.8$ (C-8'), 28.6 (C-7').

\section{Tephrosin $(3)^{14}$}

Yellow resin solid; EI/MS m/z (Int. rel.): 410 ([M] $\left.{ }^{+}, 26\right), 208$ (100), 187 (17), 165 (13), 86 (60), 84 (70), 49 (33); ${ }^{1} \mathrm{H}$ NMR (500 $\mathrm{MHz}, \mathrm{CDCl}_{3}$ ) - $\delta$ (multiplicity, $J \mathrm{~Hz}$ ): 7.73 (d, 9.0, H-11), $6.60(\mathrm{~d}$, 10.0, H-4'), 6.57 (s, H-1), 6.48 (s, H-4), 6.47 (d, 9.0, H-10), 5.55 (d, 10.0, H-5'), 4.63 (dd, 12.0, 2.5, H- $6_{\text {ax }}$ ), 4.57 (dd, 2.5, 1.0, H-6a), 4.50 (dd, 12.0, 1.0, H-6 $\mathrm{eq}_{\mathrm{eq}}$ ) 4.44 (s, OH-12a), 3.81 (s, $\left.\mathrm{OCH}_{3}-3\right), 3.78$ (s, $\left.\mathrm{OCH}_{3}-2\right), 1.45$ (s, H-7'), 1.39 (s, H-8'); ${ }^{13} \mathrm{C} \mathrm{NMR}\left(125 \mathrm{MHz}, \mathrm{CDCl}_{3}\right.$ ):

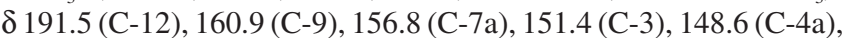
144.2 (C-2), 128.9 (C-5'), 128.7 (C-11), 115.5 (C-4'), 112.0 (C-10), 111.3 (C-11a), 109.8 (C-1), 109.3 (C-8), 108.8 (C-1a), 101.3 (C-4), 78.1 (C-6'), 76.5 (C-6a), 67.6 (C-12a), 64.0 (C-6), $56.5\left(\mathrm{OCH}_{3}-3\right)$, $56.0\left(\mathrm{OCH}_{3}-2\right), 28.7$ (C-8'), 28.4 (C-7').

\section{Larvicidal bioassay}

The samples ( 12.5 to $500 \mu \mathrm{g} / \mathrm{mL})$ were placed in a beaker $(50 \mathrm{~mL})$ and dissolved in $\mathrm{DMSO} / \mathrm{H}_{2} \mathrm{O} 1,5 \%(20 \mathrm{~mL})$. A total of 50 instar III larvae of $A$. aegypti were placed into each beaker. After $24 \mathrm{~h}$ at room temperature, the number of dead larvae was counted and lethal percentage calculated. A control using DMSO/ $\mathrm{H}_{2} \mathrm{O} 1.5 \%$ was carried out in parallel. For each sample, three independent experiments were run. ${ }^{16}$

\section{RESULTS AND DISCUSSION}

Ethanol extract of roots of T. toxicaria was fractionated and purified by classical chromatographic methods and by reversed-phase 
HPLC in order to isolat the rotenoids deguelin (1), ${ }^{13}$ 12a-hydroxy$\alpha$-toxicarol (2) $)^{13}$ and tephrosin (3). ${ }^{14}$ The structures of all compounds were established by $1 \mathrm{D}{ }^{1} \mathrm{H}$ and ${ }^{13} \mathrm{C}\left(\left\{{ }^{1} \mathrm{H}\right\}\right.$ and DEPT $)$ and $2 \mathrm{D}{ }^{1} \mathrm{H}-{ }^{1} \mathrm{H}-$ COSY, HSQC and HMBC NMR spectral data and by comparing their spectroscopy data with that reported in the literature. The configuration of the $\mathrm{B} / \mathrm{C}$-ring junction of all the rotenoids was established by ${ }^{1} \mathrm{H}$ NMR spectroscopic analysis, where the chemical shift value at $\delta$ 6.6-6.8 for $\mathrm{H}-1$ confirmed the cis-fused B/C-ring system. The absolute configuration for the three rotenoids was obtained based on CD data. ${ }^{17,18}$ The CD spectra of $\mathbf{1 , 2}$ and $\mathbf{3}$ (Figure 1) revealed a negative Cotton effect at about $330 \mathrm{~nm}[\pi \rightarrow \pi *$ transition] and a positive Cotton effect at about $360 \mathrm{~nm}[\mathrm{n} \rightarrow \pi *$ transition] (Figure 2). These data allowed assignment of the absolute configurations as $6 \mathrm{aS}, 12 \mathrm{a} S$ cis at the $\mathrm{B} / \mathrm{C}$-ring junction for compound $\mathbf{1}$ and $6 \mathrm{a} R, 12 \mathrm{a} R$ cis at the B/C-ring junction for compounds $\mathbf{2}$ and $\mathbf{3}$.

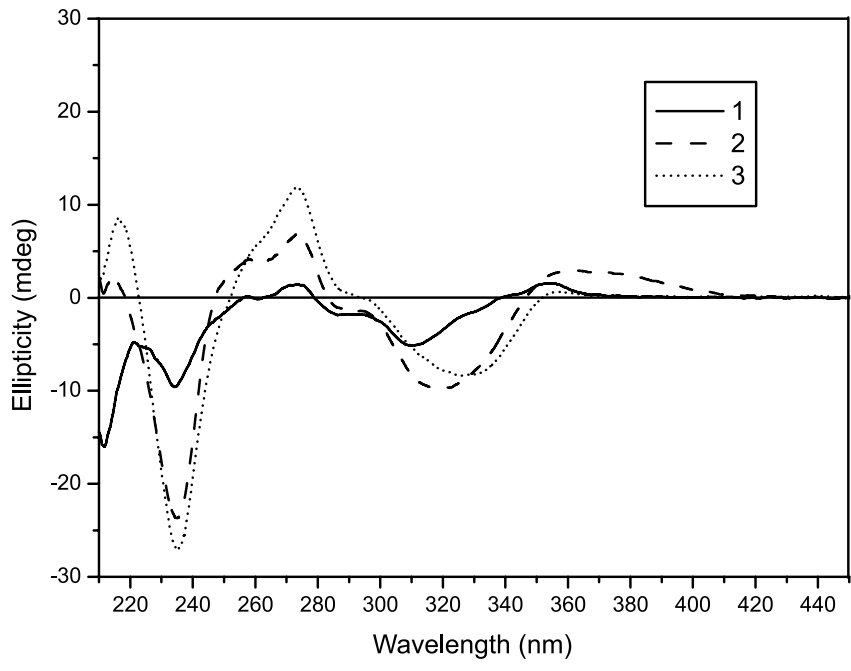

Figure 2. CD spectra of rotenoids 1 (deguelin), 2 (12a-hydroxy- $\alpha$-toxicarol) and 3 (tephrosin). Run in $\mathrm{CH}_{3} \mathrm{CN}$

Larvicidal activities of all compounds were examined using the $3^{\text {rd }}$ instar larvae of Aedes aegypti. The crude ethanol extract from roots of Tephrosia toxicaria was examined, yielding an $\mathrm{LC}_{50}$ of $47.86 \pm 2.75$ ppm whereas its active $\mathrm{CHCl}_{3}$ fraction had an $\mathrm{LC}_{50}$ of $13.80 \pm 0.80$ ppm. ${ }^{10}$ These results suggest that the rotenoids isolated from this fraction are most likely responsible for the larvicidal activity of this plant.

Within the limits of our data, some comments about the relationship between their structures and larvicidal activities are warranted. For instance, all compounds (Figure 1) isolated from $T$. toxicaria have a cis-fused B/C-ring system and methoxyl groups at C-2 and $\mathrm{C}-3$, deemed important for the larvicidal activities of rotenoids. These features were reported by Yenesew and coworkers ${ }^{8,9,19}$ who compared the activity of the aforementioned compounds, with those having trans-fused B/C-ring systems and displaying methylenedioxy in the same position. In this case, no larvicidal activity was observed.

The Table 1 shows a comparison of larvicidal activities of the compounds $\mathbf{1 - 5}$ with the Rotenone ${ }^{\circledR}$ and synthetic insecticide Temephos ${ }^{\circledR}\left[O, O^{\prime}\right.$-(thiodi-4,1-phenylene)bis $(O, O$-dimethylphosphorothioate)] used as standards. As shown in this table the activity of $\mathbf{5}$ was significantly weaker $\left(\mathrm{LC}_{50}>50\right)$ than the compounds $\mathbf{1 - 4}$ which showed an $\mathrm{LC}_{50}$ of $3.38 \pm 2.02,3.22 \pm 1.37,6.31 \pm 0.69$ and 24.55 $\pm 0.13 \mathrm{ppm}$, respectively. The lack of unsaturation at the B/C-ring junction, corresponding to the conversion of compound 5 to 4 , increases larvicidal activity significantly as reported in the literature..$^{8,19}$ Nonetheless, it must be stressed that hydroxylation of C-12a and the presence of another hydroxyl function at $\mathrm{C}-11$ had subtle effects on larvicidal activity as can be seen in Table 1 . These results showed that it is difficult to draw any conclusion regarding the structure-activity relationship of the compounds by only analyzing the presence or absence of the double bond between C-6a and C-12a. However, the importance of the lipophilicity that confers high toxicity to rotenoid $\mathbf{1}$, as is seen with Rotenone ${ }^{\circledR}$ (highly similar with regard to its lipophilic character) was noteworthy: as was analyzing the position of the hydroxyl groups that enhanced larvicidal activity, exemplified by the high efficiency of rotenoids $\mathbf{2 , 3}$ and $\mathbf{4}$.

Table 1. Larvicidal effects of the rotenoids from T. toxicaria Pers. against A. aegypti

\begin{tabular}{ccc}
\hline Compound & Name & $\mathrm{LC}_{50}(\mathrm{ppm})$ \\
\hline $\mathbf{1}$ & deguelin & $3.38 \pm 2.02$ \\
$\mathbf{2}$ & 12a-hydroxy- $\alpha$-toxicarol & $3.22 \pm 1.37$ \\
$\mathbf{3}$ & tephrosin & $6.31 \pm 0.69$ \\
$\mathbf{4}$ & $\alpha$-toxicarol & $24.55 \pm 0.13$ \\
$\mathbf{5}$ & 6a,12a-dehydro- $\alpha$-toxicarol & $>50$ \\
Control 1 & Rotenone $^{\circledast}$ & $3.16 \pm 1.53$ \\
Control 2 & Temephos $^{\circledast}$ & $1.40 \pm 0.20$ \\
\hline
\end{tabular}

This study demonstrated that the rotenoids $\mathbf{1 , 2}$ and $\mathbf{3}$ obtained from roots are the compounds responsible for the high larvicidal activity of $T$. toxicaria against mosquito larvae $A$. aegypti. Thus, this plant may serve as a suitable eco-friendly alternative to synthetic insecticides for larval mosquito control in many areas of the world.

\section{CONCLUSIONS}

The results of the present study can be useful to help promote research aimed at developing new natural larvicidal agents for the control and eradication of A. aegypti, based on bioactive chemical compounds from Brazilian plant sources. Deguelin (1), 12a-hydroxy- $\alpha$-toxicarol (2) and tephrosin (3) were identified as the larvicidal principles of the ethanol extract of the roots of T. toxicaria. The use of cultivated shrubs such as T. toxicaria may constitute a promising ecological and economically feasible approach for controlling dengue, which poses a serious health problem in tropical and subtropical countries.

\section{ACKNOWLEDGEMENTS}

The authors acknowledge the financial support provided by Brazilian Agencies CNPq, CAPES, FUNCAP and PRONEX; and are grateful to CENAUREMN - UFC, for providing the NMR spectra, to Núcleo de Endemias da Secretaria de Saúde do Estado do Ceará (NUEND), were the bioassays were performed and Prof. E. P. Nunes for botanical identification.

\section{REFERENCES}

1. Callaway, E.; Nature 2007, 448, 734.

2. Carvalho, A. F. U.; Melo, V. M. M.; Craveiro, A. A.; Machado, M. I. L.; Bantim, M. B.; Rabelo, E. F.; Mem. Inst. Oswaldo Cruz 2003, 98, 569.

3. Gubler, D.; Am. J. Trop. Med. Hyg. 1989, 40, 571.

4. Remia, K. M.; Logaswamy, S.; Indian J. N. P. Resour. 2010, 1, 208.

5. Dharmagadda, V. S. S.; Naik, S. N.; Mittal, P. K.; Vasudevan, P.; Bioresour. Technol. 2005, 96, 1235.

6. Lomonaco, D.; Santiago, G. M. P.; Ferreira, Y. S.; Arriaga, A. M. C.; Mazzetto, S. E.; Mele, G.; Vasapollo, G.; Green Chem. 2009, 11, 31. 
7. Cheng, S. S.; Huang, C. G.; Chen, W. J.; Kuo, Y. H.; Chang, S. T.; Bioresour. Technol. 2008, 99, 3617; Prajapati, V.; Tripathi, A. K.; Aggarwal, K. K.; Khanuja, S. P. S.; Bioresour. Technol. 2005, 96, 1749.

8. Yenesew, A.; Derese, S.; Midiwo, J. O.; Heydenreich, M.; Peter, M. G.; Pest Manag. Sci. 2003, 59, 1159.

9. Yenesew, A.; Derese, S.; Midiwo, J. O.; Oketch-Rabah, H. A.; Lisgarten, J.; Palmer, R.; Heydenreich, M.; Peter, M. G.; Akala, H.; Wangui, J.; Liyala, P.; Waters, N.; Phytochemistry 2003, 64, 773.

10. Ribeiro, W. H. F.; Vasconcelos, J. N.; Arriaga, A. M. C.; Oliveira, M. C. F.; Andrade-Neto, M.; Lemos, T. L. G.; Santiago, G. M. P.; Nascimento, R. F.; Mafezoli, J.; Nat. Prod. Commun. 2006, 1, 391.

11. Vasconcelos, J. N.; Lima, J. Q.; Lemos, T. L. G.; Oliveira, M. C. F.; Almeida, M. M. B.; Andrade-Neto, M.; Mafezoli, J.; Arriaga, A. M. C.; Santiago, G. M. P.; Braz-Filho, R.; Quim. Nova 2009, 32, 382.

12. Feitosa, E. M. A.; Arriaga, A. M. C.; Santiago, G. M. P.; Lemos, T. L. G.; Oliveira, M. C. F.; Vasconcelos, J. N.; Lima, J. Q.; Malcher, G. T.; Nascimento, R. F.; Braz-Filho, R.; J. Braz. Chem. Soc. 2009, 20, 375; Arriaga, A. M. C.; Rodrigues, F. E. A.; Lemos, T. L. G.; Oliveira, M.
C. F.; Lima, J. Q.; Santiago, G. M. P.; Braz-Filho, R.; Mafezoli, J.; Nat. Prod. Commun. 2007, 2, 1237.

13. Andrei, C. C.; Vieira, P. C.; Fernandes, J. B.; Da Silva, M. F. G. F.; Rodrigues-Filho, E. R.; Phytochemistry 1997, 46, 1081; Clark, E. P.; J. Am. Chem. Soc. 1931, 53, 313.

14. Ahmad, V. U.; Ali, Z.; Hussaini, S. R.; Iqbal, F.; Zahid, M.; Abbas, M.; Saba, N.; Fitoterapia 1999, 70, 443.

15. Harper, S. H.; J. Chem. Soc. 1940, 1178; Clark, E. P.; J. Am. Chem. Soc. 1930, 52, 2461

16. Oliveira, M. F.; Mattos, M. C.; Lemos, T. L. G.; Segundo, T. A.; Santiago, G. M. P.; Braz- Filho, R.; An. Acad. Bras. Cienc. 2002, 74, 211.

17. Yenesew, A.; Midiwo, J. O.; Waterman, P. G.; Phytochemistry 1998, 47, 295.

18. Slade, D.; Ferreira, D.; Marais, J. P. J.; Phytochemistry 2005, 66, 2177.

19. Yenesew, A.; Kiplagat, J. T.; Mushibe, E. K.; Derese, S.; Midiwo, J. O.; Kabaru, J. M.; Heydenreich, M.; Peter, M. G.; $11^{\text {th }}$ NAPRECA Symposium Book of Proceedings 2005, 161. 